\title{
Superparamagnetic Nanoparticles and RNAi-Mediated Gene Silencing: Evolving Class of Cancer Diagnostics and Therapeutics
}

\author{
Sanchareeka Dey and Tapas K. Maiti \\ Biotechnology Department, Indian Institute of Technology, Kharagpur 721302, India \\ Correspondence should be addressed to Tapas K. Maiti, maititapask@gmail.com \\ Received 13 February 2012; Accepted 23 April 2012 \\ Academic Editor: Haifeng Chen
}

Copyright ( $) 2012$ S. Dey and T. K. Maiti. This is an open access article distributed under the Creative Commons Attribution License, which permits unrestricted use, distribution, and reproduction in any medium, provided the original work is properly cited.

\begin{abstract}
The ever increasing death of patients affected by various types of fatal cancers is of concern worldwide. Curative attempts by radiation/chemotherapy and surgery are often a failure in the long run. Moreover, adverse side effects of such treatments burden the patients with painful survival at the last phase of their life. The failure of early diagnosis is one of the root causes of the problem. Intensive research activities are being pursued in reputed laboratories across the globe to find superior diagnostics and therapeutics. Over the last decade, a number of publications have highlighted RNA interference based silencing of cancer-related gene expression as a promising technology to tackle the aforesaid problems. Superparamagnetic iron oxide nanoparticles (SPIONs) are reported to be excellent vehicles for short-interfering RNA (siRNA). The SPION-siRNA conjugate is biocompatible, stable, and amenable to specific targeting and can cross the blood brain barrier. The issues related to their synthesis, surface properties, delivery, tracking, imaging in relevance to cancer diagnostic and therapeutic, and so forth demand an extensive review, and we have addressed these aspects in this paper. The future prospects of the technology have also been traced.
\end{abstract}

\section{Introduction}

The number of patients suffering from various fatal types of cancers (lung, breast, prostate, etc.) has been increasing worldwide, irrespective of the countries that are developed or developing. Several nonspecific treatments include radiation therapy and chemotherapy. The treatment failure continues to be very high, and multidrug resistance is known.

The adverse side effects of drugs and drug formulation vehicles are of serious concern [1]. Capecitabine, the oral prodrug for fluorouracil, for example, given to ovarian, prostate and pancreatic cancer patients develop systemic toxicity [2] including neutropenia, stomatitis, and so forth [3]. Similarly, breast cancer patients treated with anthracyclines and taxanes as well as antibody therapies (anti-HER2 drug herceptin) exhibit long-term cardiotoxicity. The blood brain barrier (BBB) is a major obstacle in the treatment of brain cancer through intravascular drug application because only a small fraction of the drug actually reaches tumor, and most local delivery methods bring neurotoxicity [4]. As a result of such healthcare complications in cancer patients receiving prolonged treatments, only palliative treatments are prescribed in many cases at the last phase of their survival. Targeted drug delivery systems (liposomes, micelles, polymer drug conjugates, etc.) have short comings of drug leakage in vivo, packaging limitations, reduced potency, and so forth.

In the last decade, several exciting articles on RNAi have been published on their potential in suppressing oncogenes by silencing. The 20-30 nucleotides double-stranded small or micro-RNAs (siRNAs or miRNAs) cause natural posttranscriptional gene silencing in eukaryotic cells [5]. The delivery of siRNAs was experimented by conjugating with natural or synthetic polymers and using nanoparticles as a vehicle. The last one are the most important because of their nontoxicity, effectiveness due to large surface area, and ability to cross tight junction of endothelial cells in blood brain barrier. Superparamagnetic nanoparticles can act as agents for effective treatment of cancers, especially brain tumor. Superparamagnetic iron oxide nanoparticles (SPIONs) have interesting properties such as biocompatibility, stability in body fluids, nonimmunogenicity, and amenability to coating/conjugation for cell-specific targeting 
and imaging/tracking. Overall, SPIONs could be designed into a multifunctional unit [6-8].

A recent article on the possibility of gene delivery by SPIONs in three-dimensional cell cultures underscores the amazing potential for this promising technology. In this paper, we review the usefulness of the versatile SPIONs with regard to their superiority as a vehicle for RNAi-mediated gene silencing. We present here their importance as an evolving new class of cancer diagnostics and therapeutics.

\section{SPION Synthesis for Biomedical Application}

When the material dimension is reduced to nanoscale, the enhanced magnetic property is superparamagnetism. Ferro- or ferri-magnetic materials at sizes on the order of tens of nanometers become a single magnetic domain and maintain one large magnetic moment. At sufficiently high temperatures (i.e., blocking temperature TB), free rotation of the particle is however induced resulting in a loss of net magnetization (i.e., their magnetization appears to be in average zero, and they are said to be in the superparamagnetic state) in the absence of an external field [42]. SPIONs are the most commonly used superparamagnetic nanoparticles for biomedical applications (i.e., immunoassays, magnetic resonance imaging, magnetic cell separation, magnetic oligonucleotide and nucleic acid separation, drug delivery, etc.). There has been intense investigations by chemists and material scientists over the synthesis of SPIONs.

SPIONs can be synthesized by either chemical or mechanical approaches. Chemical synthesis is however more suitable for the production of SPIONs of uniform size and composition [43]. A variety of synthetic processes have been adopted for the production of iron oxide nanoparticles ranging from the more conventional wet chemistry solutionbased methods to more fascinating techniques such as laser pyrolysis. The two most commonly employed methods for SPION synthesis for biomedical application include alkaline coprecipitation and microemulsion of $\mathrm{Fe} 2+$ and $\mathrm{Fe} 3+$ salts $[44,45]$.

2.1. Coprecipitation. Coprecipitation is the most commonly followed synthetic route for SPION synthesis because it is the simplest and most efficient pathway [6, 45-47]. Iron salts are coprecipitated with a strong base under aqueous conditions to yield the core of the SPION [48]. During nanoparticle formation, conditions are optimized to yield a short nucleation event followed by a slower growth phase. The end product obtained has good monodispersity [49]. The SPION core has two fates. One is the direct conjugation of the core with surface coatings, while the other is the purification and dispersion in a multistep procedure followed by surface coating [44]. The major advantage of coprecipitation is the quantity of nanoparticles that can be synthesized [50]. Another advantage is that the size and magnetic quality of the nanoparticle can be controlled by manipulating factors like ionic strength of the solution, $\mathrm{pH}$, and stoichiometry of the reactants [44]. Controlling the crystal growth step is inevitable for producing SPIONs of sub $\mathrm{nm}$ size [45]. In order to improve the uniformity and stability of SPIONs, modifications of the standard coprecipitation approach have been investigated. Synthesis of SPIONs by alkaline coprecipitation of ferric $(0.086 \mathrm{M})$ and ferrous $(0.043 \mathrm{M})$ salts has been reported [11]. SPION synthesis by coprecipitation of $\mathrm{FeCl}_{2}, \mathrm{FeCl}_{3}$, and 2,2 (ethylenedioxy)bis(ethylamine) (EDEA) in the presence of PEG has also been reported [21].

2.2. Microemulsion. This method of SPION synthesis is relatively new. Microemulsion is a thermodynamically stable, isotropic dispersion of two immiscible liquids. For waterin-oil (water in oil: W/O) microemulsions, water droplets behave as nanoreactors in a continuous phase (oil), stabilized by a monolayer of surfactant, at the interface of the two liquids [45-47]. Unlike coprecipitation method, little control of particle size and shape has been achieved by controlling factors like $\mathrm{pH}$ and reactants stoichiometry but is generally more controlled with respect to size distribution. SPIONs synthesized by microemulsion technique also suffer from poor crystallinity. This situation can, however, be handled by annealing $[44,45]$. The overall hydrodynamic radius is a critical factor in determining the particle diffusion.

Other methods for SPION preparation that are reported in the literature include thermal decomposition $[6,46,49$, $51]$, sol-gel method $[43,45,50]$, hydrothermal method [43, $47,50,51]$, polyol method, and so forth [43, 50]. Despite the difficulty faced in controlling the nanoparticle dynamics with respect to size and crystallinity, they have been used extensively for biomedical applications. The main advantages of using SPIONs for biomedical applications are (i) they aggregate only in the presence of a strong external magnetic field over an extended period of time which facilitates the particles to maintain their colloidal stability and avoid aggregation, (ii) they have greater surface area to volume ratio due to their small size, which improves its binding kinetics [52], (iii) SPIONs attached with a drug can be injected and guided through the body to target sites (i.e., tumour) by the application of an external magnetic field [45], (iv) they can be visualized by magnetic resonance imaging (MRI) $[25,37,46,49,52-54]$, and (v) they can be heated to provide hyperthermia for cancer therapy [53]. They also have magnetic susceptibilities much higher than paramagnetic materials [52]. Hence, there are several aspects for the application of SPIONs including diagnostic molecular imaging [52], delivery of drug and gene and targeted therapy [37, 45, 49, 52, 55].

\section{Commonly Used SPIONs and Their Surface Properties}

SPIONs mainly include magnetite $\left(\mathrm{Fe}_{3} \mathrm{O}_{4}\right)$, maghemite $(\gamma$ $\left.\mathrm{Fe}_{2} \mathrm{O}_{3}\right)$, and hematite $\left(\alpha-\mathrm{Fe}_{2} \mathrm{O}_{3}\right)$. Ferrites (oxides of iron mixed with other transition metal ions) have also been reported to be superparamagnetic. $\mathrm{Fe}_{3} \mathrm{O}_{4}$ and $\gamma$ - $\mathrm{Fe}_{2} \mathrm{O}_{3}$ are however apparently, most commonly employed for biomedical applications [21, 42, 45, 47]. SPION consists of an iron oxide core coated with a biocompatible polymer. It has a huge potential as carriers for biomolecules like proteins, antibodies, enzymes, and nucleic acids. SPIONs 
have low toxicity and great biocompatibility and are hence well tolerated by the biological system. Their size is similar to biomacromolecules and is therefore ideal scaffolds to produce nanobioconjugates. The different categories of SPIO, based on their overall diameter (including iron oxide core and coating), are oral SPIO (diameter $\sim 300 \mathrm{~nm}-3.5 \mu \mathrm{m}$ ); standard SPIO (SSPIO) (diameter 60-150 nm); ultrasmall SPIO (USPIO) (diameter 10-40 nm); monocrystalline iron oxide nanoparticles (MION) (diameter $\sim 10-30 \mathrm{~nm}$ ) very small superparamagnetic iron oxide nanoparticles (VSOP) (diameter $<10 \mathrm{~nm}$ ) $[6,8,26,56,57]$. A typical SPION consists of a magnetically active core with a stable core coating to which targeting ligands, imaging modalities, and therapeutic agents are anchored (see Figure 1). The function of surface coatings is to (i) prevent agglomeration of iron oxide core, (ii) enable conjugation of drug molecules, targeting ligands, imaging modalities, and so forth, to the surface, (iii) limit nonspecific cell interactions and (iv) prevent toxic elements to leach into the body during in vivo application [49]. There are many choices of coating materials like silica, gold, natural polymers (carbohydrates (e.g., dextran; starch), proteins (e.g., albumin, RGD), and lipids), and synthetic organic polymers [poly(ethyleneglycol) (PEG), and polyvinyl alcohol (PVA), polyethyleneimine (PEI)] [49, 55]. A list of biomolecules for matrix coating and their corresponding application in biomedicine has been reported $[53,55]$.

The surface of the SPIONs needs to be modified in order to attach biomolecules to the surface. Otherwise biomolecules may not bind, or bound biomolecules may interact poorly with the surface of the nanoparticles resulting in the instant release of these biomolecules during delivery. Modification through organic linkers is the preferred option as it provides a wide range of surface properties to suit biomolecules in various conditions. For example, when applying for gene and drug delivery, the most suitable surface is a positively charged one whereas to bind proteins like lysozyme and antibodies, negatively charged surface is favored. Organic linkers include amine $\left(-\mathrm{NH}_{2},-\mathrm{NHR},-\right.$ $\left.\mathrm{NR}_{2}\right)$, carboxylic acid $(-\mathrm{COOH})$, aldehyde $(-\mathrm{CHO})$, and thiol $(-\mathrm{SH})[49,55]$. For successful application, SPIONs need to be engineered carefully with respect to its size, shape, coating, and surface modifications to specifically target damaged tissue. Each of these design parameters must be thoroughly evaluated to produce a NP that can overcome biological barriers and carry out its function efficiently. A number of chemical approaches have been used for the conjugation of targeting, therapeutic, and imaging reporter molecules with NP surfaces $[49,58]$. These can be categorized as covalent linkage strategies (direct nanoparticle conjugation; click chemistry; covalent linker chemistry) and physical interactions (electrostatic; hydrophilic/hydrophobic; affinity interactions).

The choice of chemistry depends on the chemical properties of the SPION and the functional groups of the coating and ligand to be linked. SPIONs can be coated by a number of approaches (i) end-grafted polymer-coated MNP: polymers are generally anchored to the NP surface
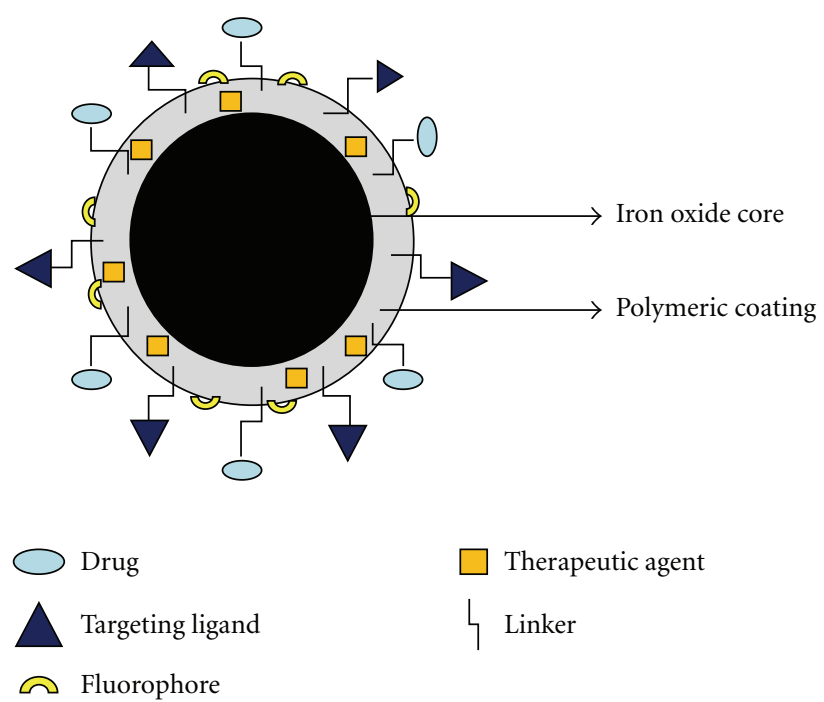

FIgURE 1: Surface modification of SPIONs. (a) Drug, (b) targeting ligand, (c) fluorophore, (d) therapeutic agent, and (e) linker.

by polymer end groups resulting in brush-like extensions, (ii) SPION fully encapsulated in polymer coating: the NP core is uniformly encapsulated by the coating by in situ and postsynthesis modification with polysaccharides and copolymers, (iii) Liposome encapsulated MNP: a shell is created around the SPION core by micelle forming molecules liposomes [49, 52] (see Figure 2).

\section{SPIONs for Cancer (Drug Delivery and Imaging)}

SPIONs have attracted a great deal of interest in biomedical research and clinical applications over the past decades specially for targeted drug delivery combined with magnetic resonance imaging (MRI) for non-invasive, early cancer detection, and treatment. Surface properties, specifically designed for cell targeting are required for this purpose. The general strategy involves creating a biocompatible polymeric or nonpolymeric coating and subsequently conjugating bioactive molecules to it. Since SPIONs only exhibit magnetic properties in the presence of an applied magnetic field, they have the advantage of being used in both in vitro as well as in vivo applications such as hyperthermia [59], magnetic drug targeting (MDT), magnetic resonance imaging (MRI), gene delivery and wide range of applications in the detection, diagnosis, and treatment of cancer. SPIONs have shown clinical efficacy in cancer drug delivery and imaging. Some formulations are now FDA-approved for use in the clinic. Some SPION formulations designed for cancer therapy have been listed in Table 1 . 


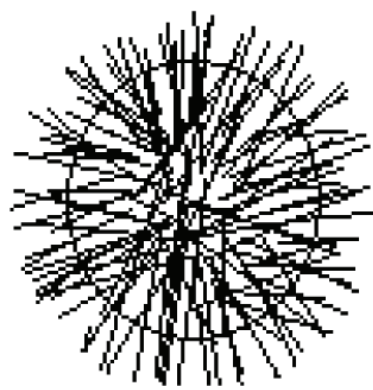

(a)

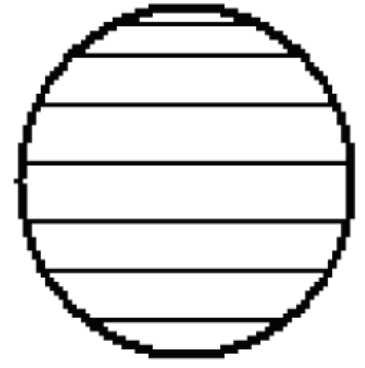

(b)

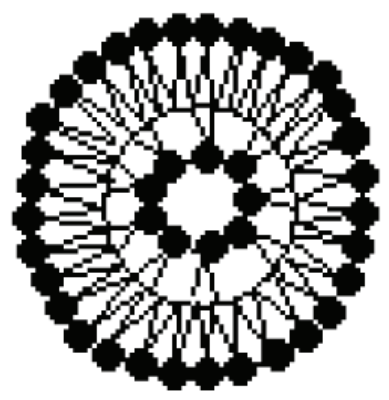

(c)

FIgURE 2: MNP structures and coating schemes. (a) End-grafted polymer coated MNP. (b) MNP fully encapsulated in polymer coating. (c) Liposome-encapsulated MNP.

\subsection{Drug Delivery}

4.1.1. Chemotherapeutic Drugs. Targeted drug delivery systems (DDSs) for cancerous cells maximize the efficiency of chemotherapy and radiotherapy and reduce its side effects as well as dosage and cost [46].

In MDT, SPIONs loaded with anticancer drugs are administrated either intravenously or intra-arterially and randomly circulated in the blood stream. When an external high-gradient magnetic field is applied at the desired site, the drug/carrier complex is accumulated at that site. Later, the drug is released via enzymatic cleavage or changes in physiological conditions, such as $\mathrm{pH}$, osmolality or temperatures. Another advantage of using SPIONs is that the success of MDT in distributing and capturing these particles can be traced by MRI. The criteria for SPIONs to be used as carriers for MDT includes a size range of 10-100 $\mathrm{nm}$ to avoid renal clearance and extravasation by the reticuloendothelial system, a strong magnetic force to overcome the drag forces from blood flow, hydrophilic surfaces to maximize blood circulation and reduce absorption by plasma proteins [46]. Conventional drugs such as mitoxantrone, doxorubicin, and methotrexate can be either attached or encapsulated in SPIONs for the treatment of tumors [9, 25, 60-63]. Carriers can be specifically designed to enhance the efficacy of these therapeutic agents. It is also possible to engineer characteristics such as loading capacities and drug release profiles by controlling structural and chemical features within the SPION conjugate.

4.1.2. Proteins and Peptides. Peptides and proteins constitute a new generation of drugs. Chlorotoxin (Cltx), a peptide with high affinity for a variety of tumors, is currently being evaluated for applications in cancer imaging and therapy. In addition to serving as a targeting agent, Cltx also exhibits the ability to inhibit tumor invasion, which is particularly useful in the treatment of highly invasive brain tumors such as gliomas $[21,64]$. The biggest barrier in using protein drugs for therapy is however its transportation across the tissue [65]. SPIONs of narrow size ranges are easily produced and coupled to proteins, enabling its easy delivery into the cell.
A number of SPION formulations have been investigated as carriers of therapeutic proteins and peptides $[10,19,21,26$, 56].

4.1.3. DNA and siRNA. Antisense and gene therapy have been areas of intense research due to their vast potential in medicine. Most of the efforts in gene therapy currently aim at cancer. For the in vivo application of DNA and siRNA, it should be efficiently and stably transferred across the cell membrane, should have a convenient blood half-life, and must be available to the tissue in optimum quantity [39]. Hence, there should be a way to deliver them noninvasively to tissues of interest. Also to conceive and optimize the delivery and treatment strategies, using clinically relevant imaging paradigms is needed. SPIONs may be designed to serve as new dual-purpose probe for the simultaneous noninvasive imaging and delivery of DNA and siRNAs to tumors (magnetofection). This technique has been successfully applied for in vitro transfection and is presently being optimized for in vivo applications $[37,49]$.

4.1.4. Targeting Ligands. A promising approach toward increasing the local accumulation of SPIONs in diseased tissue is specific targeting of cancer cells by the conjugation of targeting molecules to SPIONs that possess high affinity toward unique molecular signatures found on malignant cells. By integrating cancer cell-specific ligands, these multifunctional MNPs can serve strictly as a vehicle for drug delivery [41].

4.1.5. Magnetic Fluid Hyperthermia (MFH) Therapy. Cancerous cells are more sensitive to temperature than normal cells. Hence, Hyperthermia is a very promising treatment for cancer. Heating devices for hyperthermia include ultrasound, microwaves, laser fibers, and so forth. SPIONs can act as transducers to the tumor cells by converting AC electromagnetic energy into heat which targets only the SPION-loaded cells [67]. The use of SPIONs facilitates hyperthermia treatment because (i) they are nano-sized (they have greater specific absorption rates than micrometersized particles), (ii) magnetic (they can be localized and 
TABLE 1: SPIO-based formulation used for cancer therapy.

\begin{tabular}{|c|c|c|c|c|}
\hline SPIO preparation & SPIO coating & Cell line & Aim & REF \\
\hline (1) Thermal decomposition & PEG-PLA, cRGD ligand, and doxorubicin & SLK & $\begin{array}{l}\text { Ligand targeted drug } \\
\text { delivery and MRI }\end{array}$ & {$[9]$} \\
\hline (2) Coprecipitation & LHRH; LH/CG & MDA-MB-435S & $\begin{array}{l}\text { Ligand targeted drug } \\
\text { delivery and MRI }\end{array}$ & {$[10]$} \\
\hline (3) Coprecipitation & Dextran/PVA; Cy5.5/Cy3.5 & $\begin{array}{l}\text { Brain-derived } \\
\text { endothelial cells; } \\
\text { microglial cells }\end{array}$ & MDT and MRI & [11] \\
\hline (4) Coprecipitation & Poly(TMSMA-r-PEGMA) & LLC in mice & MRI & [12] \\
\hline (5) Coprecipitation & $\begin{array}{l}\text { DMSA ligand, rhodamine B, and fluorescein } \\
\text { diacetate maleimide }\end{array}$ & HeLa & $\begin{array}{l}\text { Fluorescent and } \\
\text { magnetic cell labeling }\end{array}$ & [13] \\
\hline (6) Thermal cross-linking & $\begin{array}{l}\text { Poly(3-(trimethoxysilyl)propyl } \\
\text { methacrylate-r-PEG methyl ether, } \\
\text { methacrylate-r-N-acryloxysuccinimide), and } \\
\text { Cy5.5 }\end{array}$ & LLC & Dual-imaging probe & {$[14]$} \\
\hline $\begin{array}{l}\text { (7) SPIONs purchased from } \\
\text { (model Resovist, Schering AG, } \\
\text { Germany) }\end{array}$ & Hydrogel & $\begin{array}{l}\text { CT- } 26 \text { mice cancer } \\
\text { cells }\end{array}$ & $\begin{array}{l}\text { Hyperthermia cancer } \\
\text { therapy }\end{array}$ & {$[15]$} \\
\hline $\begin{array}{l}\text { (8) SPIONs purchased from } \\
\text { (SHU } 555 \text { A, Resovist; Schering, } \\
\text { Berlin, Germany) }\end{array}$ & Carboxy dextran & CCL185 & $\mathrm{R} 2$ and $\mathrm{R} 2 *$ mapping & {$[16]$} \\
\hline (9) Thermal decomposition & $\begin{array}{l}\text { Poly(amidoamine) dendrimers, 6-TAMRA } \\
\text { fluorescent dye, and folic acid molecules }\end{array}$ & KB, UM-SCC-38 & MRI & [17] \\
\hline (10) Thermal cross-linking & Doxorubicin & LLC cells & MDT and MRI & [18] \\
\hline (11) Coprecipitation & $\begin{array}{l}\text { Amine-functionalized PEG silane, Alexa Fluor } \\
680 \text { (AF680) fluorochrome, and CTX }\end{array}$ & C6 & $\begin{array}{l}\text { Ligand targeted drug } \\
\text { delivery }\end{array}$ & [19] \\
\hline (12) Coprecipitation & $\begin{array}{l}\text { Glycerol monooleate, antibody HER2, } \\
\text { paclitaxel, and rapamycin }\end{array}$ & MCF7 & $\begin{array}{l}\text { Ligand targeted drug } \\
\text { delivery }\end{array}$ & [20] \\
\hline (13) Coprecipitation & PEG, CTX, and Cy5.5 & $\begin{array}{l}\text { Mouse bearing 9L } \\
\text { gliosarcoma cells }\end{array}$ & $\begin{array}{l}\text { Ligand targeted drug } \\
\text { delivery and MRI }\end{array}$ & {$[21]$} \\
\hline (14) Cross-linking & $\begin{array}{l}\text { Dextran, cRGD, epichlorohydrin, ammonia, } \\
\text { and Cy5.5 }\end{array}$ & BT-20 tumor cells & $\begin{array}{l}\text { Ligand targeted drug } \\
\text { delivery and MRI }\end{array}$ & {$[22]$} \\
\hline (15) Cross-linking & $\begin{array}{l}\text { Dextran, bombesin, epichlorohydrin, } \\
\text { ammonia, and Cy5.5 }\end{array}$ & MIA-PaCa 2 & MRI & [23] \\
\hline (16) Coprecipitation & Paclitaxel & OECM1 & MDT & [24] \\
\hline (17) Coprecipitation & $\begin{array}{l}\text { Oleic acid, pluronic, doxorubicin, and } \\
\text { paclitaxel }\end{array}$ & $\begin{array}{l}\text { MCF-7 breast } \\
\text { cancer cells }\end{array}$ & MDT and MRI & {$[25]$} \\
\hline (18) Coprecipitation & $\begin{array}{l}\text { 3-aminopropyltrimethoxysilane (APTMS), } \\
\text { Arg-Gly-Asp, and (RGD) peptides }\end{array}$ & $\begin{array}{l}\text { HaCaTras-A-5RT3, } \\
\text { A431 tumors }\end{array}$ & $\begin{array}{l}\text { Ligand targeted drug } \\
\text { delivery and MRI }\end{array}$ & [26] \\
\hline
\end{tabular}

controlled in deep tissues enabling efficient heating), and (iii) their surface can be modified for high cellular selectivity [46].

4.2. Imaging. Nanobiotechnology plays an important role in molecular imaging of cancer cells for diagnostic purpose, particularly magnetic resonance imaging (MRI) and computed tomography (CT). Significant efforts have been made in recent years to develop SPIONs for target-specific MRI contrast agents (Table 1) because of their unique paramagnetic properties, which generate significant susceptibility effects resulting in strong $\mathrm{T} 2$ and $\mathrm{T}^{*} 2$ contrast, as well as T1 effects at very low concentrations [42, 48, 68, 69]. SPION can provide critically important insights into the rate of tumor growth, degree of tumor angiogenesis, effectiveness of the treatment, and condition of normal cells by imaging proliferating cells in vivo. Researchers have recently demonstrated the use of SPIONs to image neovasculature in glioma of animal models in vitro and in vivo. FDA has approved several SPION formulations for clinical application as contrast agents in MRI. Most of the SPION preparations on sale are in a size range from $60 \mathrm{~nm}$ to some micrometers. When SPIONs are injected intravenously, they are quickly engulfed by the reticulo-endothelial system (RES) and accumulate in the liver and spleen [70]. Due to such accumulation, SPIONs have been exploited for the detection of lesions and tumors in the liver. USPIO nanoparticles, because they are much smaller than the SPIONs, do not accumulate in the RES system and are characterized by 
longer blood circulating times. Several forms of SPIONs have proven to be safe for human use [71, 72]. SPIONs can be internalized by various cell lines, which allows for magnetic labeling of the targeted cells [71]. All these features give SPIONs huge advantage for in vivo tumor imaging and drug delivery compared with other types of nanoparticles. Another advantage is the early detection of metastases which plays an important role in the management of metastatic cancer. Patients with prostate cancer who undergo surgical lymph node resection or biopsy, MRI with lymphotropic superparamagnetic nanoparticles is an alternative since it can correctly identify all patients with nodal metastases. This diagnosis is not possible with conventional MRI alone. Zhang et al. reported the fabrication of USPIO nanoparticles that exhibited a strong $\mathrm{T}^{*} 2$ contrast enhancement in gelatin gels when incubated with HUVECs in vitro in the phantom imaging experiments to access the angiogenic profiles of tumor [26].

\section{5. siRNA in Cancer Therapy}

RNA interference (RNAi) - the silencing of gene expression by double-stranded RNA molecules was first discovered by Andrew Fire, Craig Mello and colleagues in 1998 in nematode worms $C$. elegans [5]. The different stages where gene silencing can be induced by dsRNA have been depicted in Figure 3. RNAi is triggered when a cell encounters a long double-stranded RNA (dsRNA), which might have been produced by the introduction of a transgene, a viral intruder or a rogue genetic element.

RNA molecules that are a part of the RNAi mechanism include

(i) siRNA (short-interfering RNA, short 21-22 nucleotides long dsRNA);

(ii) miRNA (microRNAs, short 19-25-nucleotide long ssRNA);

(iii) tncRNA (tiny noncoding, 20-22-nucleotide long RNAs in C. elegans);

(iv) smRNA (small modulatory RNA, short dsRNA in mice) $[5]$.

RNAi technology has been widely employed for the manipulation of gene expression in mammalian and human cells to elucidate signal pathways and to identify the function of a particular gene in the genome. Many pharmaceutical companies are interested in the commercialization of RNAibased drugs for various diseases, especially in cancers. Alterations in cancer-susceptibility genes (oncogenes and tumor suppressor genes) are involved in different stages of tumor genesis like tumor initiation, progression, angiogenesis, and metastasis [73]. RNA-mediated gene-silencing is a powerful tool for identifying genes critical for the growth, differentiation, death of cells, and so forth (see Table 2). These genomic functional RNA molecules can be targeted with small fragments of their cognate sequences as the most ideal drug.

The two types of RNA molecules that are central to RNA interference are miRNA and siRNA. Here we focus

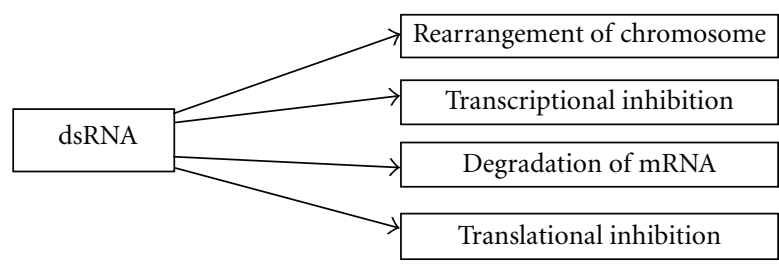

FIGURE 3: Mechanisms of selective gene silencing induced by dsRNA [78].

mainly on siRNA. siRNA is generated by the cleavage of long double-stranded RNA sequences by Dicer. After cleavage, the "sense" strand is removed, leaving a single-stranded siRNA (antisense strand) lodged inside RNA-induced silencing complex (RISC). The antisense strand is then used by RISC to guide it to the target mRNA transcript $[5,74]$.

Mammalian RNAi was first described in mouse embryos using long dsRNA. The siRNAs are emerging as new generation biodrugs because of their specific and potent triggering activity. siRNAs offer several advantages as potential new drugs since (i) siRNA does not interfere with DNA transcription which reduces concerns about possible adverse gene manipulation that might result from DNA-based gene therapy, (ii) The interaction of siRNA with mRNA rather than proteins, makes it possible to reduce the production of harmful proteins, (iii) SiRNA-based drug can target any mRNA of interest, irrespective of its cellular location, (iv) only a few siRNA molecules per cell are required to produce the desired gene silencing effect, and $(\mathrm{v})$ the identification of appropriate drug candidates using siRNA is simpler compared to traditional pharmaceuticals. Despite the several advantages of using siRNAs as potential new drugs, there are also challenges that need to be overcome in future research. (i) the silencing of nontarget genes may lead to problems in interpretation of data and potential toxicity. (ii) siRNA may result in the activation of innate immune responses upon its uncontrolled introduction inside the cell leading to several non specific events. (iii) SiRNAs are unable to enter cells by passive diffusion mechanisms since they are anionic and hydrophilic in nature [75]. Synthetically prepared siRNAs have gained wide acceptance as a laboratory tool for the validation of a target. siRNAs are highly efficient for the knockdown of gene (see Table 2) messages in vitro and in vivo that are pivotal for tumor cell growth, metastasis, angiogenesis, and chemoresistance, leading to tumor growth suppression [76]. Chemically synthesized siRNAs can be introduced into the cell either directly or by the use of plasmid and viral vectors encoding for siRNA [77].

\section{Delivery and Tracking of siRNA with SMNPS}

6.1. Delivery. Not surprisingly, genetically modified viruses (viral vectors) are the most efficient shuttles that are currently used for introducing nucleic acids into cells. For various reasons, including the possibility of biological risks, practicability, and the costs of manufacturing, researchers have however focused on synthetically designed alternatives 
TABLE 2: Development of siRNA in cancer therapy.

\begin{tabular}{|c|c|c|c|}
\hline S. no. Cell Line & Target & Result & REF \\
\hline (1) PC-3 and DU 145 & hTERT & Downregulation of hTERT inhibited cell proliferation & {$[27]$} \\
\hline (2) HT144 & RRM2 & Downregulation of RRM2 inhibited cell proliferation & {$[28]$} \\
\hline (3) H1299 and MDA-MB-468 & Ran,TPX2, SCD1 & Reduced survival of human tumor cell lines & [29] \\
\hline (4) H1299 & PTTG & $\begin{array}{l}\text { Decreasing PTTG expression reduced tumor growth in } \\
\text { vivo and in vitro }\end{array}$ & {$[30]$} \\
\hline $\begin{array}{l}\text { (5) Panc-1, PCI-19, PAN-03-JCK, and so } \\
\text { forth }\end{array}$ & S100A4 & $\begin{array}{l}\text { Knockdown of S100A4 suppressed cell growth, induced } \\
\text { apoptosis, and decreased cell migration }\end{array}$ & {$[31]$} \\
\hline (6) MDA-MB-231 and ZR751 & $\mathrm{uPA}$ & $\begin{array}{l}\text { Downregulation of decreased tumor invasion, } \\
\text { angiogenesis, and growth }\end{array}$ & {$[32]$} \\
\hline (7) A549 and H460 & Nrf2 & $\begin{array}{l}\text { Silencing inhibited tumor growth, and increasing } \\
\text { efficacy of chemotherapy }\end{array}$ & {$[33]$} \\
\hline $\begin{array}{l}\text { (8) Cx1, HCT8, HT29, HCT15, and so } \\
\text { forth. }\end{array}$ & CDCA1 and KNTC2 & $\begin{array}{l}\text { Knockdown suppressed cell proliferation and induced } \\
\text { apoptosis }\end{array}$ & {$[34]$} \\
\hline $\begin{array}{l}\text { (9) A549 } \\
\text { PC9 }\end{array}$ & $\begin{array}{l}\text { Wild type p53 } \\
\text { Surviving }\end{array}$ & $\begin{array}{l}\text { Inhibition of wildtype p53 upregulated antiapoptotic } \\
\text { survin expression. } \\
\text { Inhibition of surviving with mutated p53 depressed cell } \\
\text { proliferation }\end{array}$ & {$[35]$} \\
\hline $\begin{array}{l}\text { (10) Ten HNSCC cell lines from one nasal } \\
\text { cavity cancer (RPMI12650) }\end{array}$ & IGF2 & $\begin{array}{l}\text { Upregulation acquired resistance for RDDP in human } \\
\text { head and neck squamous cell carcinoma }\end{array}$ & {$[36]$} \\
\hline
\end{tabular}

to viruses as nucleic acid shuttles. Moreover, the delivery via viral or synthetic vectors is diffusion-limited one irrespective of the size of the nucleic acid constructs. In other words, the time required by vectors to encounter their target cells by simple diffusion and bind to their surface constitutes a major limitation for the successful delivery of nucleic acids. This limitation is even more prominent in vivo (living animals or patients) where vectors are inactivated by opsonization, immune system and degradative processes and can be purged from the target tissue by the blood stream even upon local administration. The local confinement of nucleic acid delivery is particularly an important requirement in vivo to achieve an effective dose at a target site and reduce side effects at nontarget sites. Hence, for the successful application of siRNAs in cancer treatment, the following points should be taken into consideration: size limit, to avoid difficulty in membrane penetration, degradation by exonucleases within the cell, trafficking into the appropriate cell compartment, and proper folding of the siRNA in the cell [79, 80]. In this background, the principles of magnetic drug targeting (or magnetofection) to nucleic acid delivery using magnetic nanoparticles have been adapted. The fundamental principle of magnetofection is simple. It involves the formulation of a magnetic carrier to which the siRNA is attached, adding this to the cell culture medium or injecting it systemically via the blood stream or applying it to the target tissue, and applying a magnetic field to direct the vector towards the target cells [81]. It has been reported that the driving force for increased transfection efficiency when complexed with magnetic vectors is accelerated sedimentation of nucleic acids. About $78 \%$ and $66 \%$ GFP downregulation were observed at siRNA concentrations of 32 and $8 \mathrm{nM}$, respectively, when transfected with duplexes of PEI-25Br-Mag material and
anti-GFP siRNA at Fe-to-DNA ratio of $1: 1$ [82]. Effective delivery of siRNA was achieved with LipoMag, consisting of an oleic acid-coated iron oxide core and cationic lipid shells, in mice gastric tumor models [83]. SPIONs generally consist of a magnetic iron-oxide core either encapsulated within a polymer or metallic shell or dispersed within a polymer matrix - such as silica, PVA, or dextran. The shell is then functionalized by attaching carboxyl groups, streptavidin, antibodies, and so forth. For in vitro magnetofection, the particles are usually coated with PEI, binding the nucleic acids to the surface of the SPION via charge interactions [84]. It is generally believed that positively charged nanoparticles are most efficient for siRNA delivery. In vitro magnetofection kits which utilize cationic polymer-coated MNPs are commercially available for routine laboratory use. In vivo delivery of siRNA with SPION particles is also being investigated. The role of siRNA nanoparticles as multifunctional siRNA delivery agents for effective cancer therapy has been demonstrated [40]. It would also enable real-time monitoring of the therapeutic outcome of siRNA therapy. The ability of SPIONs and poly(propyleneimine) generation 5 dendrimers (PPI G5) to enhance siRNA complexation in order to develop a multifunctional siRNA delivery system for targeted cancer therapy was investigated. The incorporation of poly(ethylene glycol) (PEG) coating and cancer-specific targeting moiety (LHRH peptide) into SPIO-PPI G5-siRNA increased the serum stability and selective internalization by cancer cells and increased the efficiency of targeted gene suppression in vitro [40]. A TAT-conjugated PEGylated magnetic polymeric liposome (TAT-PEG-MPLs) with superparamagnetic nanoparticles was successfully designed and evaluated in vitro and in vivo by [85]. Cell penetration tests were performed through fluorescein isothiocyanate 
(FITC) labeling. Results indicated that the uptake of TATPEG-MPLs by MCF-7 cells was greater than that of PEGMPLs. In vivo animal experiment, MRI, histological analysis, and atomic absorption spectrophotometry also revealed significant accumulation of TAT-PEG-MPLs nanoparticles around the target site [85].

6.2. Cellular Tracking. In spite of the successful delivery of siRNA using various nanomaterials, tracking their delivery and monitoring their transfection efficiency is an essential requirement and is difficult without a suitable tracking agent or marker [86]. The aim is to develop nanoparticles, which would not only enable cancer-specific targeting, effectively deliver sufficient dose of siRNA to target cells to induce gene silencing, but also provide the capability of carrier monitoring [49]. Recently, several strategies to track the gene delivery using nanoparticles of imaging modality have been reported [51]. SPIONs have been widely explored for this purpose (see Table 3). They are particularly useful for viewing the location and trafficking of siRNA, for in vivo applications [66].

\section{Targeting Cancer Cells with siRNA-SMNPS}

The objective of an efficient delivery system is to discharge their payloads specifically at the diseased tissue. Two approaches to serve this purpose are "passive" and "active" targeting. Passive targeting involves homing of the carriers to infected tissues, whereas active targeting relies on specific recognition of the ligands attached to the delivery vehicles by cell surface receptors on the diseased tissue $[53,68,87,88]$.

7.1. Passive Targeting. Passive targeting involves the specific migration of the nanoparticle to the target tissue mediated by the predetermined physicochemical properties of a given NP [89]. The phenomenon is based on the fact that tissues possess "leaky" vasculature allowing the extravasation and accumulation of the nanobioconjugate in the tissue more readily. Moreover, inefficient lymphatic drainage results in poor clearance of these agents, leading to selective accumulation $[49,52,90]$. With the development of longcirculating magnetic nanoparticles, exploiting the structural abnormalities in the vasculature of particular pathologies, such as tumors, has become easier. Passive targeting has been demonstrated with nanoparticles ranging from 10 to $500 \mathrm{~nm}$ in diameter [52]. SPIO probes lacking molecular specificity have been well documented for imaging biological systems via naturally directed physiological process. For passive targeting, the most important parameter is the hydrodynamic radius and the surface charge of the SPIO coating material. These parameters control the time of circulation of the nanoparticles, its accessibility to tissues, opsonization, and rate of uptake by the cell $[6,90]$. Passive targeting is available for only certain in vivo applications and does not necessarily guarantee the uptake of the SPIONs by targeted cells. Hence, they can be additionally modified with molecular targeting ligands to employ active cell targeting. SPIONs are now being designed such that they are conjugated with targeting molecules, complementary to unique receptors on target cells, to actively target only diseased tissue.

7.2. Active Targeting. The 2 major goals in the development of therapeutic agents or imaging contrast formulations are greater target selectivity and better delivery efficiency. Ideally, a therapeutic drug must be selectively enriched in the tumor lesions causing minimal damage to normal tissues $[68,91]$. Several approaches to improve the selective toxicity of anticancer therapeutics are being pursued presently of which the most commonly used method is the ligandmediated targeting of anticancer therapeutics. The basic principle that underlies ligand-targeted therapeutics is that the drug molecules are precisely associated with other antibody/ligand molecules that bind to antigens/receptors, uniquely expressed or over-expressed on target cells compared with normal tissues [68]. Cancer biomarkers include a variety of molecules such as mutant genes, RNAs, proteins, lipids, carbohydrate, and small metabolite molecules. Their altered expression or presentation on the cell surface is related to a biological change expressed as neoplasia. Identifying these cancer biomarkers could enhance the possibility to diagnose the patient's cancer molecular profile, leading to personalised and predictive medicine [92]. By coating nanoparticles with drug conjugates that contain a ligand recognized by a receptor on the target cell the selective delivery of drugs to cancer cells or cancer-associated tissues such as tumor vasculature, can be achieved [93]. Multifunctional nanoparticles can combine different functionalities including small organic molecules [37, 49, 58, 94], proteins [20, 94, 95], antibodies [58, 96-98], aptamers [49, 58, 94], and peptides $[9,10,21,26,56,58,94,95,99]$ in a single stable construct. A number of SPION systems have implemented this strategy into their design with varying success. These sophisticated multifunctional nanoparticle probes can successfully deliver itself into deep tissue, target specific cell types, and generate contrast based on targetspecific clustering. In order to target cells in vivo, it is essential to graft high-affinity ligands on the nanoparticles surface to favor specific interactions and to prevent the interactions with serum protein and subsequent capture by the RES $[100,101]$. Also to generate sufficient contrast for MR detection, adequate levels of SPION should be localized at a disease site. With this goal in mind, several approaches have been evaluated to improve the site-specific accumulation of SPION and enhance MR sensitivity. Active targeting is preferred to passive targeting as it could allow the early detection as well as more accurate staging of cancer. Numerous studies have already established the active targeting strategies to identify early cancer biomarkers [6].

siRNA "targeted" therapeutics for sequence-specific gene inhibition promise the ultimate level of precision in cancer therapy, but the hindrance lies in the poor intracellular uptake, limited blood stability, and nonspecific immune stimulation. To address these problems, sterically stabilized nanoparticles with targeting ligands have been adapted for siRNA therapeutics. Self-assembling nanoparticles have been fabricated, carrying siRNA and with Arg-Gly-Asp (RGD) peptide ligand attached at the distal end of the polyethylene 


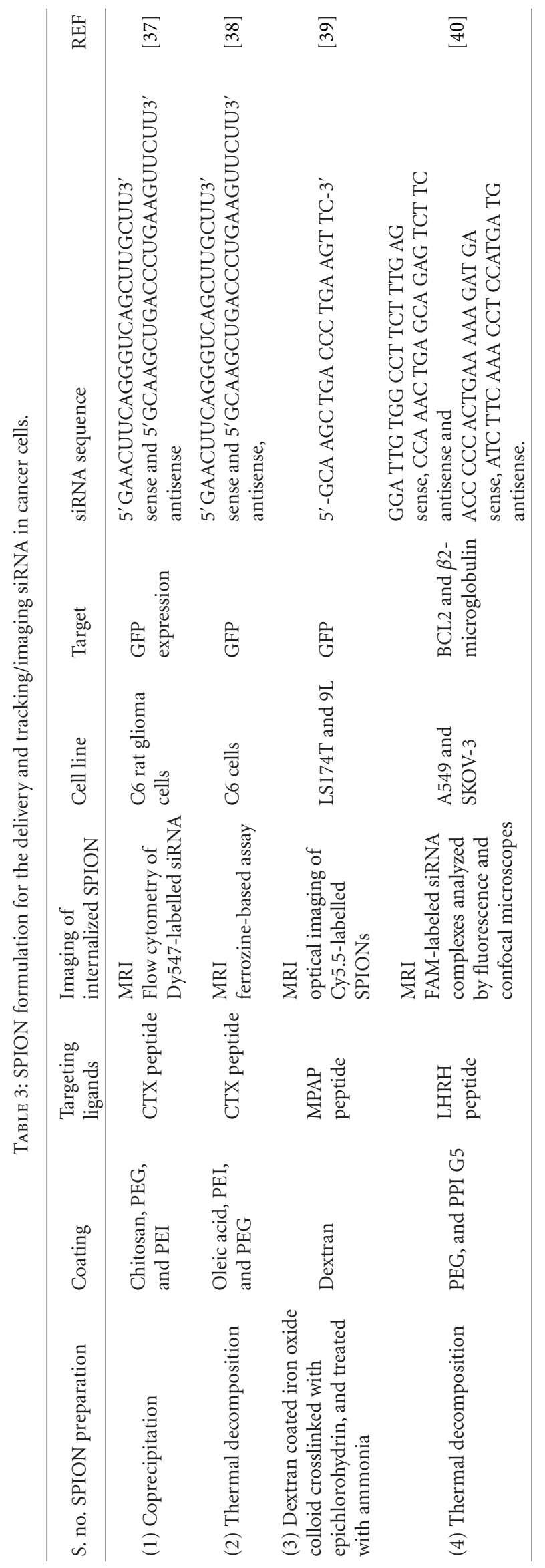


glycol (PEG) [102]. The intravenous administration of this nanovector into tumor-bearing mice targeted tumor neovasculature expressing integrins, gave selective tumor uptake, siRNA sequence-specific inhibition of vascular endothelial growth factor receptor-2 (VEGF R2) protein expression and inhibition of both tumor angiogenesis and growth rate. Hence, the results suggest achievement at two levels of targeting: tumor tissue selective delivery via the targeting ligand and gene pathway selectivity via the siRNA [102]. The possibility of utilizing TCL-SPIONs in distinct ways to develop combined therapeutic and diagnostic modalities by incorporating siRNA and small-molecular anticancer drugs have been reported [18]. A patient has completed the first successful dosing cycle with small-interfering RNA (siRNA) for the treatment of cancer in a clinical trial. The patient was administered with four doses of Calando's CALAA01, a targeted siRNA nanoparticle, over a two-week period $[92,103]$.

\section{Three-Dimensional Cell Culture, Tissue Engineering, Regenerative Medicine, and Applications of SPIONs in Three- Dimensional Self-Assembly}

Animal cell culture in 3D architecture with abilities of cell adhesion, proliferation, and differentiation is an exciting area of research in simulating in vivo conditions. Various scaffolds have been described as promising in engineering tissues to achieve the aforesaid cell/tissue properties. Neural, skeletal, and cardiovascular cells/tissues are being engineered for the purpose. The flow of liquid and gaseous ingredients carrying nutrients, drugs and cell tracking/imaging molecules assume great significance to study cell/tissue behavior in 3D architecture.

Polyethylenimine (PEI)-coated superparamagnetic nanoparticles (SPMNs) were shown to deliver interfering RNA and green fluorescent protein (GFP) plasmids through a collagen gel matrix into $3 \mathrm{D}$ cell cultures driven by an external magnetic field. PEI-coated SPMNs silenced the GFP expression with $82 \%$ efficiency [104]. These nanoparticles can also deliver small molecules and macromolecules with reduced mass transfer resistance.

Nanofiber-scaffold-mediated delivery of small-interfering RNA (siRNA) provided biomimicking topographical signals and enhanced gene silencing effects to seeded cells [105]. The feasibility of encapsulating siRNA and transfection reagent complexes was demonstrated within nanofibers comprising of a copolymer of caprolactone and ethyl ethylene phosphate. Sustained release of bioactive naked siRNA was obtained for about a month.

A few recent articles described fascinating possibilities of using SPIONs in tissue engineering and also in creating $3 \mathrm{D}$ cell-dense construct by manipulating their magnetic properties. Poly (L-lactide-co-glycolide) SPION fibrous bundles were fabricated through electrospinning technique [106]. They demonstrate 3D self-assembly of these fibrous bundles in $3 \mathrm{D}$ architecture by applying an external magnetic field. C2C12 myoblasts cell rods were formed (similar to those of native skeletal muscle tissues), and in differentiation medium they formed multinucleated myotubes.

\section{Future Prospects}

The siRNAs regulate almost all aspects of cancer (i.e., proliferation, apoptosis, metastasis, etc.) and are therefore versatile tools in cancer theragnosis. Using SPIONs as vehicle, their entry in cells/tissue, passage within cells, and the molecular mechanisms of their interactions could be well monitored.

The precise synthesis of siRNA molecules enables perfect inactivation of target mRNAs. In addition, their ability of crossing blood brain barrier will help understand brain tumor-related events which are otherwise not reachable now. As the siRNAs have the ability to silence diverse gene functions, the overall understanding of the events related to cancer diagnosis and therapy would evolve a systems biology approach in cancer treatment.

All these achievements in targeted cancer therapy using SPIONs conjugated with siRNA and targeting ligands suggest that for the first time it may be possible to tackle cancer management needs and individualize therapies by developing personalized treatments. Clinical laboratories have started using nanotechnology-based assays to detect tumor biomarkers of each patient as well as formulate the nanoparticles using the same biomarkers, carrying the specific genetic drug (i.e., siRNA) designed to knock down the biomarker protein related to that tumor. Some SPION formulations approved clinically include Feridex IV and Endorem for liver and spleen imaging, Ferumoxytol for iron replacement therapy, Combidex for imaging lymph node metastases, and Lumiren and Gastromark for bowel imaging $[45,49,52,107]$. Ferumoxtran-10 is a commercially available USPIO [108-110].

Targeted-specific immune cells in detecting metastatic liver in vivo by tagging $\beta$-glucan with SPION and accumulation in Kupffer cells were confirmed by MRI [111]. The further possibility of real-time study of in vivo migration and differentiation of stem cells is likely to enable imaging of all aspects of differentiation and development continuously [112]. A recent publication [113] on the achievement of delivering both hydrophilic and hydrophobic drugs by oligo-/multil-amellar hybrid SPION-liposome nanostructures based on phosphatidylcholine indicates the more versatile nature of SPION-mediated drug delivery. The encapsulation of the SPION inside multi-lamellar structure helped stabilize them against aggregation and sedimentation for 3 months. The vistas of SPION-siRNA diagnosis and therapy are depicted in Figure 4.

\section{Conclusion}

(i) microRNAs (miRNAs) are nonprotein-coding RNAs that control diverse gene targets and can induce silencing of many genes. Short-interfering RNAs (siRNAs) are 21-22 nucleotide long dsRNAs generated by dicer cleavage of long dsRNAs and can bind to nontranslated region of mRNAs resulting in degradation of target mRNAs. Chemically synthesized siRNAs could be used as biodrugs, for treatment of cancer; 


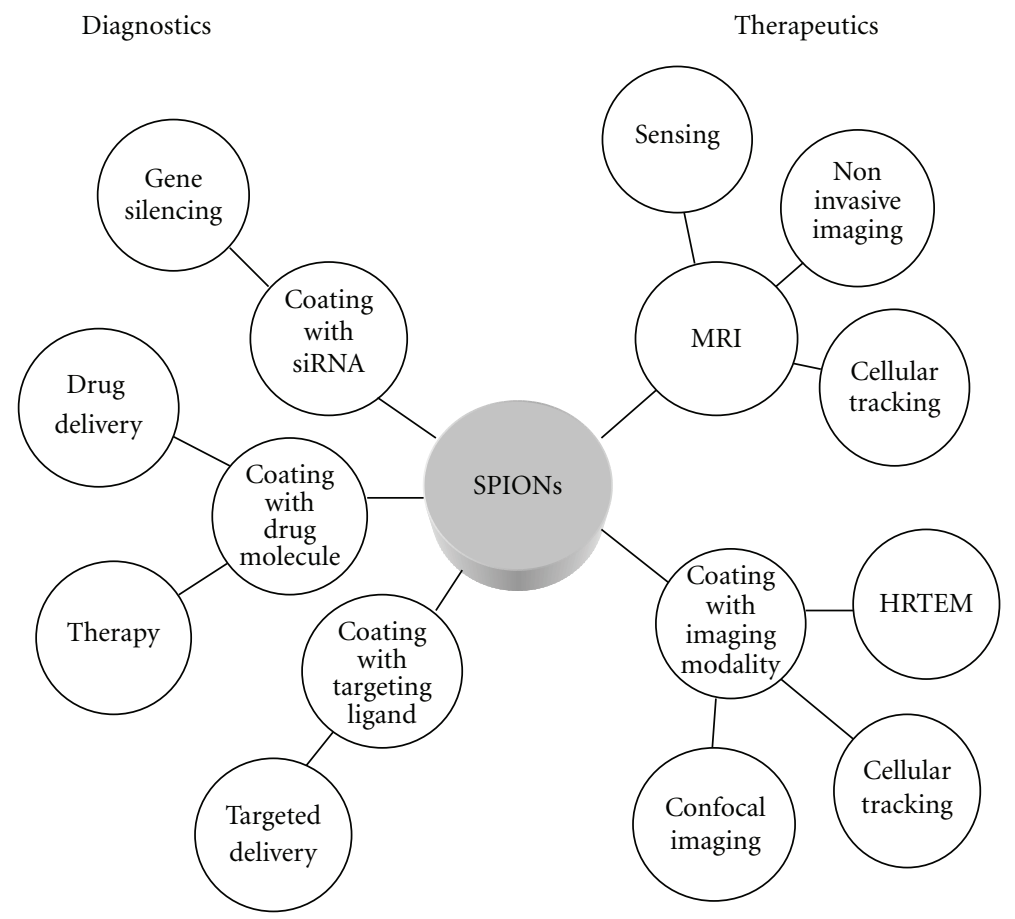

FIGURE 4: Prospects of diagnosis and therapy using SPION-siRNA conjugate.

(ii) superparamagnetic nanoparticles are excellent biocompatible vehicles for siRNA and can cross blood brain barrier. Superparamagnetic iron oxide (magnetite, maghemite, etc.) nanoparticles (SPIONs), coated with suitable linker molecules, can conjugate with a variety of target biomolecules including fluorophore for non-invasive imaging and siRNAs for gene silencing. SPIONs have also been used as cancer drug delivery systems;

(iii) SPIONs could commonly be synthesized by coprecipitation and microemulsification techniques, and the former is proved to be superior;

(iv) SPIONs have also been used in magnetic fluid hyperthermia (MFH) therapy for cancer by employing them as transducers for converting AC electromagnetic energy to heat in target cancer cells, that are more sensitive to heat than normal cells;

(v) commercial products like Combidex and Endorem have already been used in Europe for the early detection of metastases;

(vi) the possibility of achieving 3D tissue architecture in SPION-coated biomaterial fibers is an exciting incentive in research in simulating in vivo conditions in vitro.

\section{References}

[1] A. J. Tije, J. Verweij, W. J. Loos, and A. Sparreboom, "Pharmacological effects of formulation vehicles: implications for cancer chemotherapy," Clinical Pharmacokinetics, vol. 42, no. 7, pp. 665-685, 2003.

[2] C. M. Walko and C. Lindley, "Capecitabine: a review," Clinical Therapeutics, vol. 27, no. 1, pp. 23-44, 2005.

[3] L. J. M. Oostendorp, P. F. M. Stalmeier, A. R. T. Donders, W. T. A. van der Graaf, and P. B. Ottevanger, "Efficacy and safety of palliative chemotherapy for patients with advanced breast cancer pretreated with anthracyclines and taxanes: a systematic review," The Lancet Oncology, vol. 12, no. 11, pp. 1053-1061, 2011.

[4] D. R. Groothuis, "The blood-brain and blood-tumor barriers: a review of strategies for increasing drug delivery," NeuroOncology, vol. 2, no. 1, pp. 45-49, 2000.

[5] C. D. Novina and P. A. Sharp, "The RNAi revolution," Nature, vol. 430, no. 6996, pp. 161-164, 2004.

[6] D. L. J. Thorek, A. K. Chen, J. Czupryna, and A. Tsourkas, "Superparamagnetic iron oxide nanoparticle probes for molecular imaging," Annals of Biomedical Engineering, vol. 34, no. 1, pp. 23-38, 2006.

[7] K. K. Jain, "Application of nanobiotechnology in cancer therapeutics," in Pharmaceutical Perspectives of Cancer Therapeutics, Y. Lu and R. I. Mahato, Eds., pp. 245-268, Springer, New York, NY, USA, 2009.

[8] Z. Liu, F. Kiessling, and J. Gätjens, "Advanced nanomaterials in multimodal imaging: design, functionalization, and biomedical applications," Journal of Nanomaterials, vol. 2010, Article ID 894303, 2010.

[9] N. Nasongkla, E. Bey, J. Ren et al., "Multifunctional polymeric micelles as cancer-targeted, MRI-ultrasensitive drug delivery systems," Nano Letters, vol. 6, no. 11, pp. 2427-2430, 2006.

[10] C. Leuschner, C. S. S. R. Kumar, W. Hansel, W. Soboyejo, J. Zhou, and J. Hormes, "LHRH-conjugated magnetic iron oxide nanoparticles for detection of breast cancer metastases," Breast Cancer Research and Treatment, vol. 99, no. 2, pp. 163-176, 2006.

[11] F. Cengelli, D. Maysinger, F. T. Monnet et al., "Interaction of functionalized superparamagnetic iron oxide nanoparticles with brain structures," Journal of Pharmacology and Experimental Therapeutics, vol. 318, no. 1, pp. 108-116, 2006. 
[12] H. Lee, E. Lee, D. K. Kim, N. K. Jang, Y. Y. Jeong, and S. Jon, "Antibiofouling polymer-coated superparamagnetic iron oxide nanoparticles as potential magnetic resonance contrast agents for in vivo cancer imaging," Journal of the American Chemical Society, vol. 128, no. 22, pp. 7383-7389, 2006.

[13] F. Bertorelle, C. Wilhelm, J. Roger, F. Gazeau, C. Ménager, and V. Cabuil, "Fluorescence-modified superparamagnetic nanoparticles: intracellular uptake and use in cellular imaging," Langmuir, vol. 22, no. 12, pp. 5385-5391, 2006.

[14] H. Lee, M. K. Yu, S. Park et al., "Thermally cross-linked superparamagnetic iron oxide nanoparticles: synthesis and application as a dual imaging probe for cancer in vivo," Journal of the American Chemical Society, vol. 129, no. 42, pp. 12739-12745, 2007.

[15] H. Y. Tseng, C. Y. Lee, Y. H. Shih, X. Z. Lin, and G. B. Lee, "Hyperthermia cancer therapy utilizing superparamagnetic nanoparticles," in Proceedings of the IEEE International Conference on Nano/Micro Engineered and Molecular Systems (NEMS '07), vol. 19, pp. 163-166, January 2007.

[16] R. Kuhlpeter, H. Dahnke, L. Matuszewski et al., "R2 and R2* mapping for sensing cell-bound superparamagnetic nanoparticles: in vitro and murine in vivo testing," Radiology, vol. 245, no. 2, pp. 449-457, 2007.

[17] K. J. Landmark, S. D. Maggio, J. Ward et al., "Synthesis, characterization, and in vitro testing of superparamagnetic iron oxide nanoparticles targeted using folic acid-conjugated dendrimers," American Chemical Society Nano, vol. 2, no. 4, pp. 773-783, 2008.

[18] M. K. Yu, Y. Y. Jeong, J. Park et al., "Drug-loaded superparamagnetic iron oxide nanoparticles for combined cancer imaging and therapy in vivo," Angewandte Chemie - International Edition, vol. 47, no. 29, pp. 5362-5365, 2008.

[19] O. Veiseh, J. W. Gunn, F. M. Kievit et al., "Inhibition of tumor-cell invasion with chlorotoxin-bound superparamagnetic nanoparticles," Small, vol. 5, no. 2, pp. 256-264, 2009.

[20] F. Dilnawaz, A. Singh, C. Mohanty, and S. K. Sahoo, "Dual drug loaded superparamagnetic iron oxide nanoparticles for targeted cancer therapy," Biomaterials, vol. 31, no. 13, pp. 3694-3706, 2010.

[21] C. Sun, K. Du, C. Fang et al., "PEG-mediated synthesis of highly dispersive multifunctional superparamagnetic nanoparticles: their physicochemical properties and function in vivo," American Chemical Society Nano, vol. 4, no. 4, pp. 2402-2410, 2010.

[22] X. Montet, K. Montet-Abou, F. Reynolds, R. Weissleder, and L. Josephson, "Nanoparticle imaging of integrins on tumor cells," Neoplasia, vol. 8, no. 3, pp. 214-222, 2006.

[23] X. Montet, R. Weissleder, and L. Josephson, "Imaging pancreatic cancer with a peptide-nanoparticle conjugate targeted to normal pancreas," Bioconjugate Chemistry, vol. 17, no. 4, pp. 905-911, 2006.

[24] J. R. Hwu, Y. S. Lin, T. Josephrajan et al., "Targeted paclitaxel by conjugation to iron oxide and gold nanoparticles," Journal of the American Chemical Society, vol. 131, no. 1, pp. 66-68, 2009.

[25] T. K. Jain, J. Richey, M. Strand, D. L. L. Pelecky, C. A. Flask, and V. Labhasetwar, "Magnetic nanoparticles with dual functional properties: drug delivery and magnetic resonance imaging," Biomaterials, vol. 29, no. 29, pp. 4012-4021, 2008.

[26] C. Zhang, M. Jugold, E. C. Woenne et al., "Specific targeting of tumor angiogenesis by RGD-conjugated ultrasmall superparamagnetic iron oxide particles using a clinical 1.5T magnetic resonance scanner," Cancer Research, vol. 67, no. 4, pp. 1555-1562, 2007.

[27] P. Gandellini, M. Folini, R. Bandiera et al., "Down-regulation of human telomerase reverse transcriptase through specific activation of RNAi pathway quickly results in cancer cell growth impairment," Biochemical Pharmacology, vol. 73, no. 11, pp. 1703-1714, 2007.

[28] M. E. Davis, J. E. Zuckerman, C. H. J. Choi et al., "Evidence of RNAi in humans from systemically administered siRNA via targeted nanoparticles," Nature, vol. 464, no. 7291, pp. 10671070, 2010.

[29] S. E. Morgan-Lappe, L. A. Tucker, X. Huang et al., "Identification of Ras-related nuclear protein, targeting protein for Xenopus kinesin-like protein 2, and stearoyl-CoA desaturase 1 as promising cancer targets from an RNAi-based screen," Cancer Research, vol. 67, no. 9, pp. 4390-4398, 2007.

[30] S. S. Kakar and M. T. Malik, "Suppression of lung cancer with siRNA targeting PTTG," International Journal of Oncology, vol. 29, no. 2, pp. 387-395, 2006.

[31] T. Tabata, N. Tsukamoto, A. A. I. Fooladi et al., "RNA interference targeting against S100A4 suppresses cell growth and motility and induces apoptosis in human pancreatic cancer cells," Biochemical and Biophysical Research Communications, vol. 390, no. 3, pp. 475-480, 2009.

[32] S. Kunigal, S. S. Lakka, C. S. Gondi, N. Estes, and J. S. Rao, "RNAi-mediated downregulation of urokinase plasminogen activator receptor and matrix metalloprotease-9 in human breast cancer cells results in decreased tumor invasion, angiogenesis and growth," International Journal of Cancer, vol. 121, no. 10, pp. 2307-2316, 2007.

[33] A. Singh, S. B. Adamsky, R. K. Thimmulappa et al., "RNAimediated silencing of nuclear factor erythroid-2-related factor 2 gene expression in non-small cell lung cancer inhibits tumor growth and increases efficacy of chemotherapy," Cancer Research, vol. 68, no. 19, pp. 7975-7984, 2008.

[34] N. Kaneko, K. Miura, Z. Gu et al., "siRNA-mediated knockdown against CDCA1 and KNTC2, both frequently overexpressed in colorectal and gastric cancers, suppresses cell proliferation and induces apoptosis," Biochemical and Biophysical Research Communications, vol. 390, no. 4, pp. 1235-1240, 2009.

[35] K. Yonesaka, K. Tamura, T. Kurata et al., "Small interfering RNA targeting survivin sensitizes lung cancer cell with mutant p53 to adriamycin," International Journal of Cancer, vol. 118, no. 4, pp. 812-820, 2006.

[36] T. Ogawa, K. Ogawa, K. Shiga et al., "Upregulation of IGF2 is associated with an acquired resistance for cisdiamminedichloroplatinum in human head and neck squamous cell carcinoma," European Archives of Oto-RhinoLaryngology, vol. 267, no. 10, pp. 1599-1606, 2010.

[37] O. Veiseh, F. M. Kievit, C. Fang et al., "Chlorotoxin bound magnetic nanovector tailored for cancer cell targeting, imaging, and siRNA delivery," Biomaterials, vol. 31, no. 31, pp. 8032-8042, 2010.

[38] H. Mok, O. Veiseh, C. Fang et al., "PH-sensitive siRNA nanovector for targeted gene silencing and cytotoxic effect in cancer cells," Molecular Pharmaceutics, vol. 7, no. 6, pp. 1930-1939, 2010.

[39] Z. Medarova, W. Pham, C. Farrar, V. Petkova, and A. Moore, "In vivo imaging of siRNA delivery and silencing in tumors," Nature Medicine, vol. 13, no. 3, pp. 372-377, 2007. 
[40] O. Taratula, O. Garbuzenko, R. Savla, Y. A. Wang, H. He, and T. Minko, "Multifunctional nanomedicine platform for cancer specific delivery of sirna by superparamagnetic iron oxide nanoparticles-dendrimer complexes," Current Drug Delivery, vol. 8, no. 1, pp. 59-69, 2011.

[41] J. H. Zhou, L. Huang, W. W. Wang et al., "Prostate cancer targeted MRI nanoprobe based on superparamagnetic iron oxide and copolymer of poly(ethylene glycol) and polyethyleneimin," Chinese Science Bulletin, vol. 54, pp. 3137-3146, 2009.

[42] Q. A. Pankhurst, J. Connolly, S. K. Jones, and J. Dobson, "Applications of magnetic nanoparticles in biomedicine," Journal of Physics D, vol. 36, no. 13, pp. R167-R181, 2003.

[43] M. A. Willard, L. K. Kurihara, E. E. Carpenter, S. Calvin, and V. G. Harris, "Chemically prepared magnetic nanoparticles," International Materials Reviews, vol. 49, no. 3-4, pp. 125-170, 2004.

[44] S. R. Dave and X. Gao, "Monodisperse magnetic nanoparticles for biodetection, imaging, and drug delivery: a versatile and evolving technology," in Nanomedicine and Nanobiotechnology, J. R. Baker, Ed., vol. 1, pp. 583-609, John Wiley \& Sons, Hoboken, NJ, USA, 2009.

[45] M. Mahmoudi, S. Sant, B. Wang, S. Laurent, and T. Sen, "Superparamagnetic iron oxide nanoparticles (SPIONs): development, surface modification and applications in chemotherapy," Advanced Drug Delivery Reviews, vol. 63, no. 1-2, pp. 24-46, 2011.

[46] M. M. Lin, D. K. Kim, A. J. E. Haj, and J. Dobson, "Development of superparamagnetic iron oxide nanoparticles (SPIONS) for translation to clinical applications," IEEE Transactions on Nanobioscience, vol. 7, no. 4, pp. 298-305, 2008.

[47] A. Figuerola, R. D. Corato, L. Manna, and T. Pellegrino, "From iron oxide nanoparticles towards advanced iron-based inorganic materials designed for biomedical applications," Pharmacological Research, vol. 62, no. 2, pp. 126-143, 2010.

[48] M. H. Amtenbrink, B. V. Rechenberg, and H. Hofmann, "Superparamagnetic nanoparticles for biomedical applications," in Nanostructured Materials for Biomedical Applications, M. C. Tan, G. M. Chow, and L. Ren, Eds., chapter 5, pp. 119-148, Transworld Research Network, Trivandrum, India, 2009.

[49] O. Veiseh, J. W. Gunn, and M. Zhang, "Design and fabrication of magnetic nanoparticles for targeted drug delivery and imaging," Advanced Drug Delivery Reviews, vol. 62, no. 3, pp. 284-304, 2010.

[50] S. Laurent, D. Forge, M. Port et al., "Magnetic iron oxide nanoparticles: synthesis, stabilization, vectorization, physicochemical characterizations and biological applications," Chemical Reviews, vol. 108, no. 6, pp. 2064-2110, 2008.

[51] J. Kim, Y. Piao, and T. Hyeon, "Multifunctional nanostructured materials for multimodal imaging, and simultaneous imaging and therapy," Chemical Society Reviews, vol. 38, no. 2, pp. 372-390, 2009.

[52] C. Sun, J. S. H. Lee, and M. Zhang, "Magnetic nanoparticles in MR imaging and drug delivery," Advanced Drug Delivery Reviews, vol. 60, no. 11, pp. 1252-1265, 2008.

[53] T. Neuberger, B. Schöpf, H. Hofmann, M. Hofmann, and B. von Rechenberg, "Superparamagnetic nanoparticles for biomedical applications: possibilities and limitations of a new drug delivery system," Journal of Magnetism and Magnetic Materials, vol. 293, no. 1, pp. 483-496, 2005.
[54] C. W. Lu, Y. Hung, J. K. Hsiao et al., "Bifunctional magnetic silica nanoparticles for highly efficient human stem cell labeling," Nano Letters, vol. 7, no. 1, pp. 149-154, 2007.

[55] S. C. McBain, H. H. P. Yiu, and J. Dobson, "Magnetic nanoparticles for gene and drug delivery," International Journal of Nanomedicine, vol. 3, no. 2, pp. 169-180, 2008.

[56] C. Zhang, B. Wängler, B. Morgenstern et al., "Silicaand alkoxysilane-coated ultrasmall superparamagnetic iron oxide particles: a promising tool to label cells for magnetic resonance imaging," Langmuir, vol. 23, no. 3, pp. 1427-1434, 2007.

[57] D. Högemann, L. Josephson, R. Weissleder, and J. P. Basilion, "Improvement of MRI probes to allow efficient detection of gene expression," Bioconjugate Chemistry, vol. 11, no. 6, pp. 941-946, 2000.

[58] J. R. McCarthy and R. Weissleder, "Multifunctional magnetic nanoparticles for targeted imaging and therapy," Advanced Drug Delivery Reviews, vol. 60, no. 11, pp. 1241-1251, 2008.

[59] F. Sonvico, S. Mornet, S. Vasseur et al., "Folate-conjugated iron oxide nanoparticles for solid tumor targeting as potential specific magnetic hyperthermia mediators: synthesis, physicochemical characterization, and in vitro experiments," Bioconjugate Chemistry, vol. 16, no. 5, pp. 1181-1188, 2005.

[60] C. Alexiou, R. Jurgons, C. Seliger, O. Brunke, H. Iro, and S. Odenbach, "Delivery of superparamagnetic nanoparticles for local chemotherapy after intraarterial infusion and magnetic drug targeting," Anticancer Research, vol. 27, no. 4, pp. 20192022, 2007.

[61] F. M. Kievit, F. Y. Wang, C. Fang et al., "Doxorubicin loaded iron oxide nanoparticles overcome multidrug resistance in cancer in vitro," Journal of Controlled Release, vol. 152, no. 1, pp. 76-83, 2011.

[62] N. Kohler, C. Sun, J. Wang, and M. Zhang, "Methotrexatemodified superparamagnetic nanoparticles and their intracellular uptake into human cancer cells," Langmuir, vol. 21, no. 19 , pp. 8858-8864, 2005.

[63] C. Alexiou, R. Jurgons, R. Schmid et al., "In vitro and in vivo investigations of targeted chemotherapy with magnetic nanoparticles," Journal of Magnetism and Magnetic Materials, vol. 293, no. 1, pp. 389-393, 2005.

[64] J. Deshane, C. C. Garner, and H. Sontheimer, "Chlorotoxin inhibits glioma cell invasion via matrix metalloproteinase2," Journal of Biological Chemistry, vol. 278, no. 6, pp. 41354144, 2003.

[65] R. Solaro, F. Chiellini, and A. Battisti, "Targeted delivery of protein drugs by nanocarriers," Materials, vol. 3, pp. 19281980, 2010.

[66] J. H. Lee, K. Lee, S. H. Moon, Y. Lee, T. G. Park, and J. Cheon, "All-in-One target-cell-specific magnetic nanoparticles for simultaneous molecular imaging and siRNA delivery," Angewandte Chemie, vol. 48, no. 23, pp. 4174-4179, 2009.

[67] J. L. Phillips, "A topical review of magnetic fluid hyperthermia," Journal of Science and Health at the University of Alabama, pp. 14-28, 2005.

[68] X. Wang, L. Yang, Z. Chen, and D. M. Shin, "Application of nanotechnology in cancer therapy and imaging," $C A: A$ Cancer Journal for Clinicians, vol. 58, no. 2, pp. 97-110, 2008.

[69] C. E. Sjögren, C. Johansson, A. Naevestad, P. C. Sontum, K. Briley-Saebø, and A. K. Fahlvik, "Crystal size and properties of superparamagnetic iron oxide (SPIO) particles," Magnetic Resonance Imaging, vol. 15, no. 1, pp. 55-67, 1997.

[70] C. C. Berry and A. S. G. Curtis, "Functionalisation of magnetic nanoparticles for applications in biomedicine," Journal of Physics D, vol. 36, no. 13, pp. R198-R206, 2003. 
[71] M. F. Kircher, J. R. Allport, E. E. Graves et al., "In vivo high resolution three-dimensional imaging of antigenspecific cytotoxic T-lymphocyte trafficking to tumors," Cancer Research, vol. 63, no. 20, pp. 6838-6846, 2003.

[72] K. M. Hauff, R. Rothe, R. Scholz et al., "Intracranial thermotherapy using magnetic nanoparticles combined with external beam radiotherapy: results of a feasibility study on patients with glioblastoma multiforme," Journal of NeuroOncology, vol. 81, no. 1, pp. 53-60, 2007.

[73] F. L. Tan and J. Q. Yin, "Application of RNAi to cancer research and therapy," Frontiers in Bioscience, vol. 10, no. 2, pp. 1946-1960, 2005.

[74] Y. Tomaru and Y. Hayashizaki, "Cancer research with noncoding RNA," Cancer Science, vol. 97, no. 12, pp. 1285-1290, 2006.

[75] Y. K. Oh and T. G. Park, "siRNA delivery systems for cancer treatment," Advanced Drug Delivery Reviews, vol. 61, no. 10, pp. 850-862, 2009.

[76] A. W. Tong, Y. A. Zhang, and J. Nemunaitis, "Small interfering RNA for experimental cancer therapy," Current Opinion in Molecular Therapeutics, vol. 7, no. 2, pp. 114-124, 2005.

[77] M. Masiero, G. Nardo, S. Indraccolo, and E. Favaro, "RNA interference: implications for cancer treatment," Molecular Aspects of Medicine, vol. 28, no. 1, pp. 143-166, 2007.

[78] R. Agami, "RNAi and related mechanisms and their potential use for therapy," Current Opinion in Chemical Biology, vol. 6, no. 6, pp. 829-834, 2002.

[79] A. Khaled, S. Guo, F. Li, and P. Guo, "Controllable selfassembly of nanoparticles for specific delivery of multiple therapeutic molecules to cancer cells using RNA nanotechnology," Nano Letters, vol. 5, no. 9, pp. 1797-1808, 2005.

[80] L. Huang and J. Li, "Targeted delivery of RNAi therapeutics for cancer therapy," Nanomedicine, vol. 5, no. 10, pp. 14831486, 2010.

[81] U. Schillinger, T. Brill, C. Rudolph et al., "Advances in magnetofection-magnetically guided nucleic acid delivery," Journal of Magnetism and Magnetic Materials, vol. 293, no. 1, pp. 501-508, 2005.

[82] O. Mykhaylyk, D. Vlaskou, N. Tresilwised, P. Pithayanukul, W. Möller, and C. Plank, "Magnetic nanoparticle formulations for DNA and siRNA delivery," Journal of Magnetism and Magnetic Materials, vol. 311, no. 1, pp. 275-281, 2007.

[83] Y. Namiki, T. Namiki, H. Yoshida et al., "A novel magnetic crystal-lipid nanostructure for magnetically guided in vivo gene delivery," Nature Nanotechnology, vol. 4, no. 9, pp. 598606, 2009.

[84] J. Dobson, "Gene therapy progress and prospects: magnetic nanoparticle-based gene delivery," Gene Therapy, vol. 13, no. 4, pp. 283-287, 2006.

[85] H. Wang, S. Zhang, Z. Liao et al., "PEGlated magnetic polymeric liposome anchored with TAT for delivery of drugs across the blood-spinal cord barrier," Biomaterials, vol. 31, no. 25, pp. 6589-6596, 2010.

[86] S. S. Suri, H. Fenniri, and B. Singh, "Nanotechnology-based drug delivery systems," Journal of Occupational Medicine and Toxicology, vol. 2, 16 pages, 2007.

[87] M. De, P. S. Ghosh, and V. M. Rotello, "Applications of nanoparticles in biology," Advanced Materials, vol. 20, no. 22, pp. 4225-4241, 2008.

[88] F. M. Kievit and M. Zhang, "Surface engineering of iron oxide nanoparticles for targeted cancer therapy," Accounts of Chemical Research, vol. 44, no. 10, pp. 853-862, 2011.
[89] H. Maeda, J. Wu, T. Sawa, Y. Matsumura, and K. Hori, "Tumor vascular permeability and the EPR effect in macromolecular therapeutics: a review," Journal of Controlled Release, vol. 65, no. 1-2, pp. 271-284, 2000.

[90] R. Sinha, G. J. Kim, S. Nie, and D. M. Shin, "Nanotechnology in cancer therapeutics: bioconjugated nanoparticles for drug delivery," Molecular Cancer Therapeutics, vol. 5, no. 8, pp. 1909-1917, 2006.

[91] Y. Gao, X. L. Liu, and X. R. Li, "Research progress on siRNA delivery with nonviral carriers," International Journal of Nanomedicine, vol. 6, pp. 1017-1025, 2011.

[92] M. Wang and M. Thanou, "Targeting nanoparticles to cancer," Pharmacological Research, vol. 62, no. 2, pp. 90-99, 2010.

[93] Y. Liu, H. Miyoshi, and M. Nakamura, "Nanomedicine for drug delivery and imaging: a promising avenue for cancer therapy and diagnosis using targeted functional nanoparticles," International Journal of Cancer, vol. 120, no. 12, pp. 2527-2537, 2007.

[94] N. Sanvicens and M. P. Marco, "Multifunctional nanoparticles-properties and prospects for their use in human medicine," Trends in Biotechnology, vol. 26, no. 8, pp. 425433, 2008.

[95] O. Veiseh, C. Sun, J. Gunn et al., "Optical and MRI multifunctional nanoprobe for targeting gliomas," Nano Letters, vol. 5, no. 6, pp. 1003-1008, 2005.

[96] Y. Zhang, N. Kohler, and M. Zhang, "Surface modification of superparamagnetic magnetite nanoparticles and their intracellular uptake," Biomaterials, vol. 23, no. 7, pp. 1553-1561, 2002.

[97] Y. M. Huh, Y. W. Jun, H. T. Song et al., "In vivo magnetic resonance detection of cancer by using multifunctional magnetic nanocrystals," Journal of the American Chemical Society, vol. 127, no. 35, pp. 12387-12391, 2005.

[98] F. Hu, L. Wei, Z. Zhou, Y. Ran, Z. Li, and M. Gao, "Preparation of biocompatible magnetite nanocrystals for in vivo magnetic resonance detection of cancer," Advanced Materials, vol. 18, no. 19, pp. 2553-2556, 2006.

[99] A. Moore, Z. Medarova, A. Potthast, and G. Dai, "In vivo targeting of underglycosylated MUC-1 tumor antigen using a multimodal imaging probe," Cancer Research, vol. 64, no. 5, pp. 1821-1827, 2004.

[100] C. Wilhelm, C. Billotey, J. Roger, J. N. Pons, J. C. Bacri, and F. Gazeau, "Intracellular uptake of anionic superparamagnetic nanoparticles as a function of their surface coating," Biomaterials, vol. 24, no. 6, pp. 1001-1011, 2003.

[101] A. K. Gupta, C. Berry, M. Gupta, and A. Curtis, "Receptormediated targeting of magnetic nanoparticles using insulin as a surface ligand to prevent endocytosis," IEEE Transactions on Nanobioscience, vol. 2, no. 4, pp. 255-261, 2003.

[102] R. M. Schiffelers, A. Ansari, J. Xu et al., "Cancer siRNA therapy by tumor selective delivery with ligand-targeted sterically stabilized nanoparticle," Nucleic Acids Research, vol. 32, no. 192, p. 10, 2004.

[103] O. C. Farokhzad and R. Langer, "Impact of nanotechnology on drug delivery," American Chemical Society Nano, vol. 3, pp. 16-20, 2010.

[104] H. Zhang, M. Y. Lee, M. G. Hogg, J. S. Dordick, and S. T. Sharfstein, "Gene delivery in three-dimensional cell cultures by superparamagnetic nanoparticles," American Chemical Society Nano, vol. 4, no. 8, pp. 4733-4743, 2010.

[105] P. O. Rujitanaroj, Y. C. Wang, J. Wang, and S. Y. Chew, "Nanofiber-mediated controlled release of siRNA complexes 
for long term gene-silencing applications," Biomaterials, vol. 32, no. 25, pp. 5915-5923, 2011.

[106] W. Y. Lee, W. Y. Cheng, Y. C. Yeh et al., "Magnetically directed self-assembly of electrospun superparamagnetic fibrous bundles to form three-dimensional tissues with a highly ordered architecture," Tissue Engineering, vol. 17, no. 6, pp. 651-661, 2011.

[107] D. J. Bharali and S. A. Mousa, "Emerging nanomedicines for early cancer detection and improved treatment: current perspective and future promise," Pharmacology \& Therapeutics, vol. 128, no. 2, pp. 324-335, 2010.

[108] M. G. Harisinghani, M. A. Saksena, P. F. Hahn et al., "Ferumoxtran-10-enhanced MR lymphangiography: does contrast-enhanced imaging alone suffice for accurate lymph node characterization?" American Journal of Roentgenology, vol. 186, no. 1, pp. 144-148, 2006.

[109] R. Sharma, S. Saini, P. R. Ros et al., "Safety profile of ultrasmall superparamagnetic iron oxide ferumoxtran-10: phase II clinical trial data," Journal of Magnetic Resonance Imaging, vol. 9, no. 2, pp. 291-294, 1999.

[110] W. M. L. L. G. Deserno, M. G. Harisinghani, M. Taupitz et al., "Urinary bladder cancer: preoperative nodal staging with ferumoxtran-10-enhanced MR imaging," Radiology, vol. 233, no. 2, pp. 449-456, 2004.

[111] H. Vu-Quang, H. Muthiah, H. J. Lee et al., "Immune cellspecific delivery of beta-glucan-coated iron oxide nanoparticles for diagnosing liver metastasis by MR imaging," Carbohydrate Polymers, vol. 87, pp. 1159-1168, 2012.

[112] S. Haque and G. R. Fuhr, "New system for real time study of in vivo migration and differentiation of stem cells," Microsystem Technologies, vol. 17, no. 1, pp. 47-58, 2011.

[113] A. Floris, A. Ardu, A. Musinu et al., "SPION@liposomes hybrid nanoarchitectures with high density SPION association," Soft Matter, vol. 7, no. 13, pp. 6239-6247, 2011. 

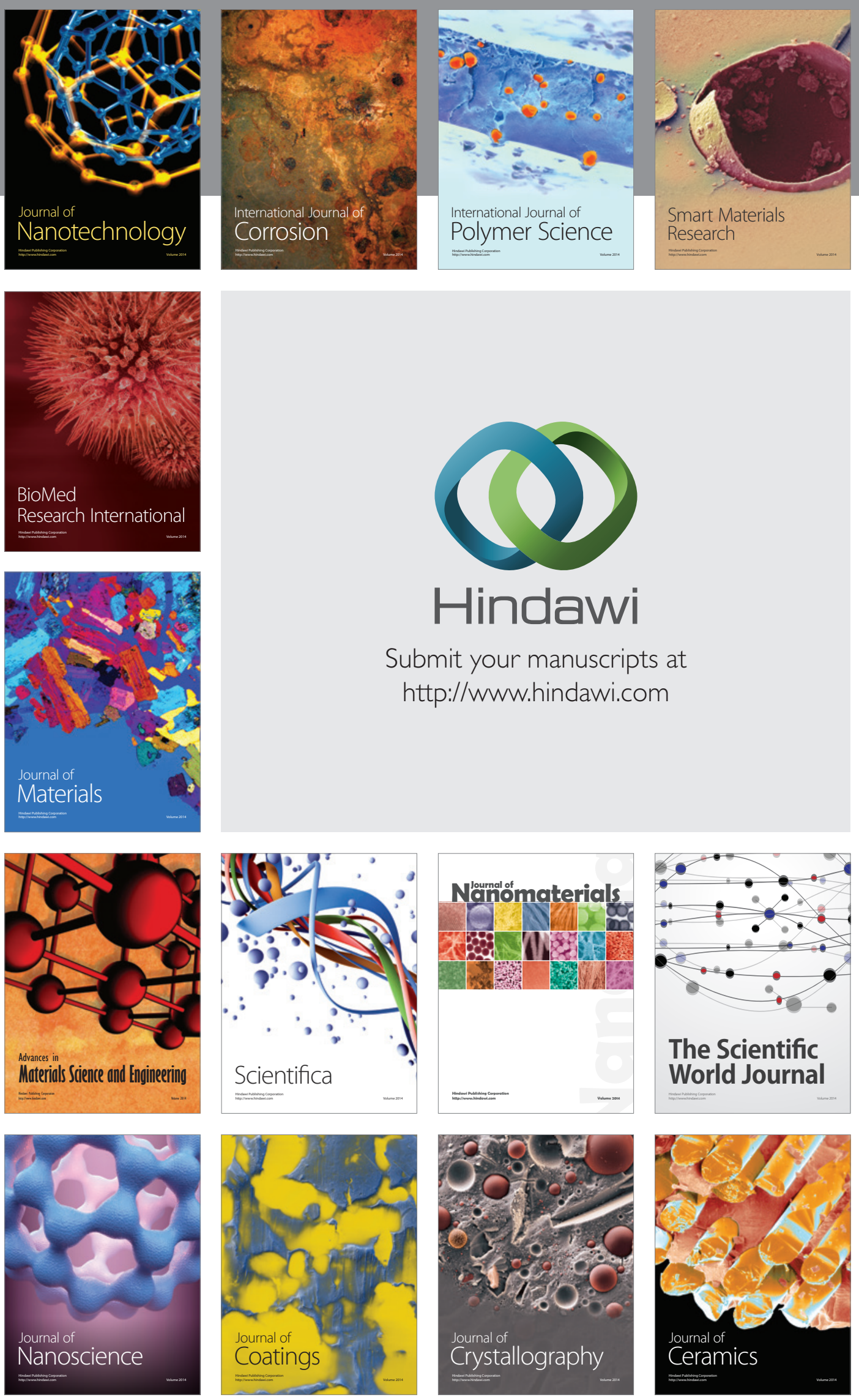

The Scientific World Journal

Submit your manuscripts at

http://www.hindawi.com

\section{World Journal}

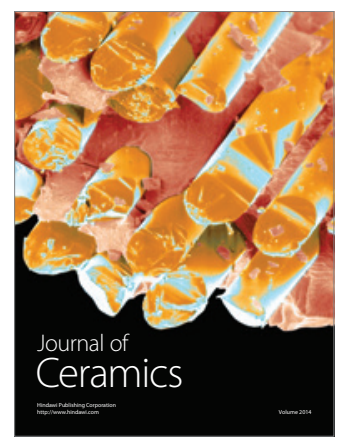

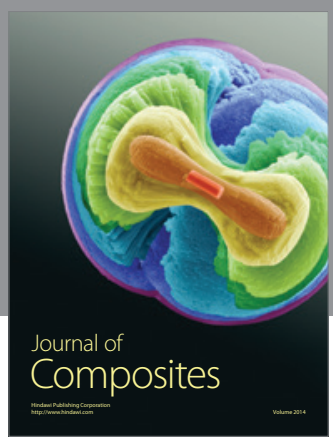
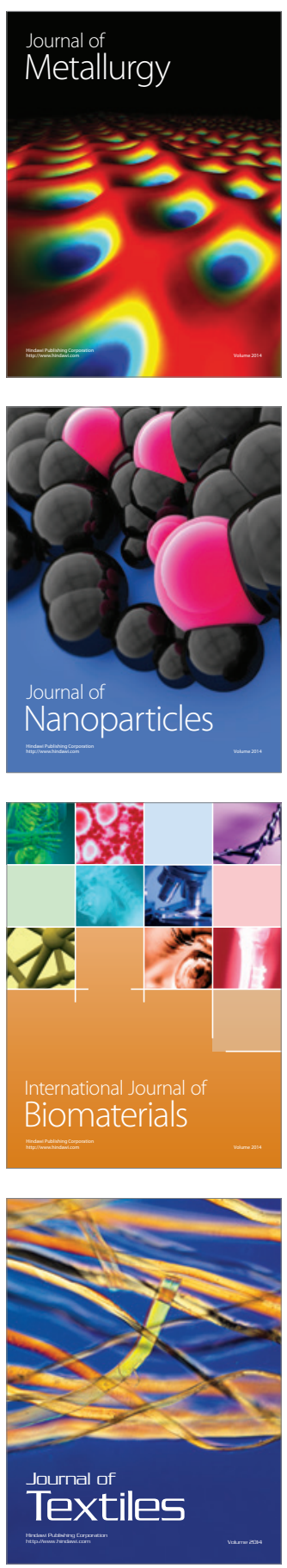